\title{
A POSSIBLE RHEOLOGICAL MODEL OF GUM CANDIES
}

\author{
Gy. CSIMA*, L.D. DÉNES and E. VoZÁRY \\ Department of Physics and Control, Faculty of Food Science, Corvinus University of Budapest \\ H-1118 Budapest, Somlói út 14-16. Hungary
}

(Received: 14 April 2014; accepted: 22 July 2014)

\begin{abstract}
An appropriate rheological model can be used in production of good quality gum candy required by consumers. For this purpose Creep-Recovery Test (CRT) curves were recorded with a Stable Micro System TA.XT-2 precision texture analyser with $75 \mathrm{~mm}$ diameter cylinder probe on gum candies purchased from the local market. The deformation speed was $0.2 \mathrm{~mm} \mathrm{~s}^{-1}$, the creeping- and recovering time was $60 \mathrm{~s}$, while the loading force was set to $1 \mathrm{~N}, 2 \mathrm{~N}, 5 \mathrm{~N}, 7 \mathrm{~N}$, and $10 \mathrm{~N}$. The two-element Kelvin-Voigt-model, a three-element model, and the four-element Burgers-model were fitted on the recorded creep data, and then the parameters of the models were evaluated. The best fitting from the used models was given by the Burgers model.
\end{abstract}

Keywords: Burgers model, gum candy, rheological modelling, texture analyser

The quality of foods can be described by both sensory and physical properties (SzCZESNIAK, 2001). The texture and its change can be characterized by rheological parameters: LAMBERTMERETEI and co-workers (2010) evaluated the changes of hardness, chewiness, gumminess, cohesiveness, and springiness of bread crumb after addition of bread improver. KASZAB and co-workers $(2008,2011)$ determined the deformation work and stiffness of carrot texture during non-ideal storage. From consumer's view the main quality properties of gum candies are also textural properties. From the producer's view, the quality and the texture of gum candy has to be described by such rheological test that is objective and models the chewing process.

The gum candy is sucrose based, combined semisolid gel, which contains approximately $10 \%$ gelatine. The sugar content (sucrose, glucose syrup, and dextrose in certain proportion) ensures the required texture profile, while the gelatine secures the typical viscoelastic rheological behaviour (Моноs, 1993). The origin, the quality, and the quantity of applied gelatine determine the main quality and sensory properties of candy (Моноs, 2010).

According to MitchelL's (1980) comprehensive study of gel rheology, the majority of food material gels show linear viscoelastic behaviour up to strain of 0.1 range. If the strain is higher than 0.1 , the creep and the stress relaxation of gels would suggest the move and the brake of non-covalent cross links under stress.

The gelatine is a biopolymer protein, obtained by hydrolytic degradation of collagen. Native conformation of collagen is a triple helix held together by inter-chain hydrogen bonding. Above $37{ }^{\circ} \mathrm{C}$ in aqueous solutions the gelatine molecules exist as separate, disordered chains (coils). When a solution containing around $1 \% \mathrm{w} / \mathrm{w}$ gelatine is cooled to room temperature, the gelatine molecules form an infinite network cross-linked by hydrogen bonding (MARFIL et al., 2012). The role of the coil-helix transition in this mechanism has

* To whom correspondence should be addressed.

Phone: +36-1-482-6023; fax: +36-1-482-6361; e-mail: gyorgy.csima@uni-corvinus.hu 
been thoroughly investigated. Gelatine gels are quite soft and flexible, and the gel strength is dependent on the gelatine concentration (MoHos, 2010).

There are lots of papers in the literature about properties of combined gelatine gels, but few about saccharine/gelatine combined gels. Hardness of gelatine gels can be increased with adding for example gellan and/or calcium ions to gel as shown by texture profile analysis on gellan/pectin mixed gels (LAU et al., 2000). The effect of gellan/gelatine ratio and the added calcium ion on gel texture elasticity, hardness, and cohesiveness were obvious, but optimal proportion was not given.

DeMars and Ziegler (2001) investigated the texture, the sensory properties, and the microstructure of gelatine/pectin gels like gum candies in the function of composition. The addition of pectin to a gelatine gummy gel reduced the strain at facture and influenced the stress of facture depending on the pectin and gelatine concentration. The stress and the strain at facture were in good correlation with sensory firmness and elasticity. At high total polymer and pectin concentrations, phase separation and coalescence were incomplete.

The texture of viscoelastic food materials, and so the texture of gum candy, too, can be described with various viscoelastic rheological models (Mitchell, 1980; BAGLEY, 1983). The creep under constant stress can be described with several rheological models: two-element (Kelvin-Voigt model), three-element, four-element (Burgers model) models (SITKEI, 1981; Figura \& TeiXeira, 2007), or in some cases the stretched exponential model can also be used (ZsivánOvits, 2007). The relaxation processes under constant deformation can be also characterized with various rheological models.

Our earlier Creep-Recovery Test (CRT) measurements - at the request of the manufacturer - gave the describing characterization of viscoelastic properties of gum candy (CSIMA \& VOZÁRY, 2013). Some parameters of CRT curves, the maximal and elastic deformation, were determined in the function of deforming force, of deformation speed, and of creeping time. The creeping part of CRT permits the approach of measured creeping curve under constant stress with rheological models.

The aim of our work presented here was to approach the creeping part of CRT curve of gum candy with various rheological models and to evaluate the rheological parameters of the model. Comparing the accuracy of approach for various models, a possible rheological model of gum candy can be given.

\section{Materials and methods}

\subsection{Materials}

For the experiments gum candies purchased from local market were used. The gum candies originated from the same production and had the same shape. The overall size of the samples is $2 \mathrm{~cm} \times 1 \mathrm{~cm} \times 1 \mathrm{~cm}$ with a weight of about $2.40 \mathrm{~g}$. Based on the manufacturer's information, the gum candies contain glucose syrup, sugar, gelatine, dextrose, natural colour, aroma, and taste components from fruit and vegetables, and are covered with bee and carnauba wax to avoid the sticking of gum candies to each other and to prevent candy from loosing moisture. All measurements were done at room temperature.

\subsection{Methods}

The CRT describing viscoelastic properties (BAGLEY, 1983) is a complex rheological measuring method, which contains three parts. At first the sample is compressed with a constant deformation speed until the preset loading force is reached. After that, the preset 
constant loading force is held for a preset time, this period is named creeping. At the beginning of the third part called recovering, the loading force decreases to zero and the relaxation of deformation is measured for the same time as the creeping was endured.

The experiments were executed with a TA.XT-2 precision texture analyser (Stable Micro System, UK). 'Force measurement in compression' mode with 'relaxation test' method was used with a cylinder metal plate of $75 \mathrm{~mm}$ diameter. The speed of cylinder was $0.2 \mathrm{~mm} \mathrm{~s}^{-1}$. On the samples CRT curves were recorded with $1 \mathrm{~N}, 2 \mathrm{~N}, 5 \mathrm{~N}, 7 \mathrm{~N}$, and $10 \mathrm{~N}$ loading force values. The creeping and recovering time was $60 \mathrm{~s}$. The parameters (force, time) were chosen on the basis of our earlier experiments (CSIMA \& VOZÁRY, 2013). The data acquisition rate was 10 points pro seconds. In every setting 20 samples were measured and evaluated.

Csima and co-workers (2010) found that the little sample size and the specific nonplanar shape and surface could cause errors in the measured results. To avoid these possible errors, a $75 \mathrm{~mm}$ diameter probe was used, which was bigger than the sample size. The texture analyser was not able to implement instantaneous loading and off-load, so at the start and at the end of the creeping period measuring errors were found (e.g. overshoot in measured force values).

The recorded force - deformation - time data series of CRT curves were handled with Texture Exponent 1.21 (Stable Micro System), R Project 3.0.1 (R Foundation for Statistical Computing, Vienna, Austria) and MS® Office 2003 Excel SP3 software. The used curve evaluating method was very similar to the curve fitting and modelling procedure used by DÉNES and co-workers (2012) in case of light intensity curves. A smoothing with SavitzkyGolay method was used to eliminate the relative high noise of force and deformation measurements.

The creeping period was cut out, then the deformation data series were moved to a common time starting point (normalization). For the normalized data series the strain $(\varepsilon)$ was calculated from the measured deformation and the original height of sample.

The strain curves as the function of normalized time data were approached with various (Fig. 1.A, B, and C) rheological models. The stress at the beginning of creeping time is $\sigma_{0}$, calculated as a ratio of the acting, constant force and the contact surface of sample.
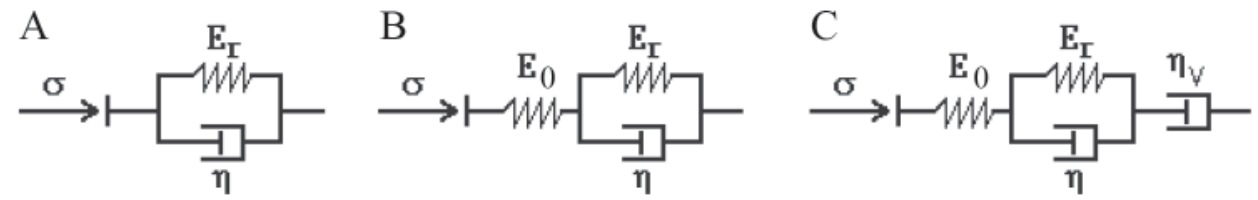

Fig. 1. Schematic figures of used rheological models. A: Kelvin-Voigt model, B: Three element model, C: Burgers model. Index ' 0 ': initial value; index ' $r$ ': retardation of strain; index ' $v$ ': residual, plastic deformation

The relative deformation, $\varepsilon$, depends on time, t, according to Eq. 1 (Kelvin-Voigt model), Eq. 2 (three-element model) and Eq. 3 (Burgers model) (SiTKEI, 1981).

$$
\begin{gathered}
\varepsilon(t)=\frac{\sigma_{0}}{E_{r}}\left(1-e^{-t / T_{r}}\right), \text { where } T_{r}=\frac{\eta}{E_{r}} \\
\varepsilon(t)=\frac{\sigma_{0}}{E_{0}}+\frac{\sigma_{0}}{E_{r}}\left(1-e^{-t / T_{r}}\right), \text { where } T_{r}=\frac{\eta}{E_{r}}
\end{gathered}
$$




$$
\varepsilon(t)=\frac{\sigma_{0}}{E_{0}}+\frac{\sigma_{0}}{E_{r}}\left(1-e^{-t / T_{r}}\right)+\frac{\sigma_{0}}{\eta_{v}} t \text {, where } T_{r}=\frac{\eta}{E_{r}}
$$

The $E_{\mathrm{r}}, E_{0}$ and $\eta_{v}, \eta$ are the elastic modulus and viscosity of Hooke and Newton elements on Figure 1. For the easier calculation procedure the general form of fitted model was the following: Equation 4 (three-element model) and Equation 5 (Burgers model).

$$
\begin{gathered}
\varepsilon(t)=a+b \cdot\left(1-e^{-t / c}\right) \\
\varepsilon(t)=a+b \cdot t+c \cdot\left(1-e^{-t / d}\right)
\end{gathered}
$$

From the $a, b, c$ and $d$ values the $E_{\mathrm{r}}, E_{0}$ and $\eta_{v}, \eta$ rheological parameters were determined.

\section{Results and discussion}

A typical measured CRT curve is shown in Figure 2. The model fitting was applied only for the creeping part.



Fig. 2. Typical CRT curve. $\triangle$ : loading force; +: measured deformation

The Kelvin-Voigt model (Fig. 1A) describes the creeping, if the loading is instantaneous and constant. But in our case the creep period can be observed after continuously increasing load (while the preset force is reached) and the deformation is the sum of deformation reached under increasing force and the deformation of creeping. The Kelvin-Voigt model, according to the Equation 1., describes only the creeping period, therefore this model is not appropriate. Developing with further elements, the three-element model (Fig. 1B) and the four-element model, the Burgers model (Fig. 1C) can be used for more precisely describing the creeping behaviour of semisolid materials (SitKeI, 1981; Мohos, 2010). Bagley (1983) suggested the use of Burgers model for modelling the viscoelastic behaviour in case of food materials. 
The approach of measured point can be seen more precisely with four-element Burgers model than with three-element model (Fig. 3). The gum candy shows a continuously increasing creep deformation under constant force (measured points), and this increasing deformation can be described well only by the four-element model. In Eq. 3 there is a $\frac{\sigma_{0}}{\eta_{v}} t$ member, which also continuously increases in time, while in Eq. 2 there is no such expression.

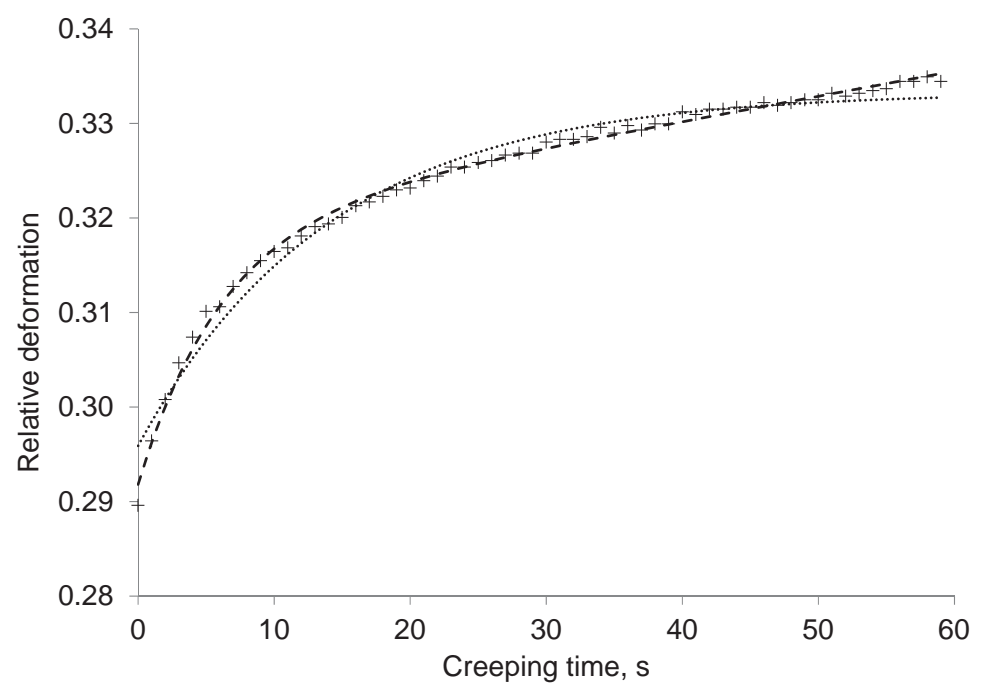

Fig. 3. Fitted model curves on measured strain data.

+: Measured strain, $\cdots \cdot \cdots$ : model with 3 elements, $----:$ model with four elements

The statistical analysis of fitting (Table 1) confirmed that the fitting was closer with Burgers model than with three-element model: The summa of residuum squares, the mean of root of square error (RMSEP), and the correlation coefficient $\left(\mathrm{R}^{2}\right)$ show also better fit with Burgers model.

Table 1. Statistical parameters of fitting three element model and Burgers model

\begin{tabular}{|c|c|c|c|}
\hline \multirow{3}{*}{  } & \multicolumn{3}{|c|}{ Three-element model } \\
\hline & $\Sigma$ residuum $^{2}$ & RMSEP & $\mathrm{R}^{2}$ \\
\hline & & Mean \pm SD & \\
\hline 1 & $1.716 \mathrm{E}-03 \pm 2.663 \mathrm{E}-04$ & $1.686 \mathrm{E}-03 \pm 1.355 \mathrm{E}-04$ & $0.9771 \pm 2.834 \mathrm{E}-03$ \\
\hline 2 & $1.283 \mathrm{E}-03 \pm 1.279 \mathrm{E}-04$ & $1.459 \mathrm{E}-03 \pm 7.374 \mathrm{E}-05$ & $0.9803 \pm 1.433 \mathrm{E}-03$ \\
\hline 5 & $1.136 \mathrm{E}-03 \pm 1.275 \mathrm{E}-04$ & $1.373 \mathrm{E}-03 \pm 7.734 \mathrm{E}-05$ & $0.9840 \pm 1.263 \mathrm{E}-03$ \\
\hline 7 & $1.018 \mathrm{E}-03 \pm 1.503 \mathrm{E}-04$ & $1.298 \mathrm{E}-03 \pm 9.470 \mathrm{E}-05$ & $0.9848 \pm 1.373 \mathrm{E}-03$ \\
\hline 10 & $1.230 \mathrm{E}-03 \pm 7.619 \mathrm{E}-04$ & $1.396 \mathrm{E}-03 \pm 3.197 \mathrm{E}-04$ & $0.9840 \pm 5.632 \mathrm{E}-03$ \\
\hline
\end{tabular}


Table 1. cont

\begin{tabular}{|c|c|c|c|}
\hline \multirow{3}{*}{ 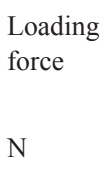 } & \multicolumn{3}{|c|}{ Four-element model (Burgers) } \\
\hline & $\Sigma$ residuum $^{2}$ & RMSEP & $\mathrm{R}^{2}$ \\
\hline & \multicolumn{3}{|c|}{ Mean \pm SD } \\
\hline 1 & $3.512 \mathrm{E}-04 \pm 4.145 \mathrm{E}-05$ & $7.632 \mathrm{E}-04 \pm 4.514 \mathrm{E}-05$ & $0.9952 \pm 9.259 \mathrm{E}-04$ \\
\hline 2 & $2.906 \mathrm{E}-04 \pm 2.541 \mathrm{E}-05$ & $6.948 \mathrm{E}-04 \pm 3.034 \mathrm{E}-05$ & $0.9955 \pm 5.150 \mathrm{E}-04$ \\
\hline 5 & $2.316 \mathrm{E}-04 \pm 2.573 \mathrm{E}-05$ & $6.199 \mathrm{E}-04 \pm 3.349 \mathrm{E}-05$ & $0.9967 \pm 3.929 \mathrm{E}-04$ \\
\hline 7 & $2.155 \mathrm{E}-04 \pm 4.015 \mathrm{E}-05$ & $5.964 \mathrm{E}-04 \pm 5.438 \mathrm{E}-05$ & $0.9968 \pm 4.417 \mathrm{E}-04$ \\
\hline 10 & $2.436 \mathrm{E}-04 \pm 1.775 \mathrm{E}-04$ & $6.166 \mathrm{E}-04 \pm 1.624 \mathrm{E}-04$ & $0.9969 \pm 1.393 \mathrm{E}-03$ \\
\hline
\end{tabular}

The applied loading force has effect on all coefficients. The values of coefficients of both models are shown in Table 2.

\begin{tabular}{|c|c|c|c|c|c|}
\hline \multirow{3}{*}{ 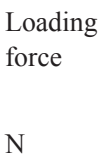 } & \multicolumn{5}{|c|}{ Three-element model } \\
\hline & \multicolumn{2}{|c|}{$a\left(=\sigma_{0} / E_{0}\right)$} & \multicolumn{2}{|c|}{$b\left(=\sigma_{0} / E_{\mathrm{r}}\right)$} & $c\left(=T_{\mathrm{r}}=\eta / E_{\mathrm{r}}\right)$ \\
\hline & \multicolumn{5}{|c|}{ Mean \pm SD } \\
\hline 1 & \multicolumn{2}{|c|}{$0.2016 \pm 1.957 \mathrm{E}-02$} & \multicolumn{2}{|c|}{$4.415 \mathrm{E}-02 \pm 3.554 \mathrm{E}-03$} & $12.93 \pm 0.5117$ \\
\hline 2 & \multicolumn{2}{|c|}{$0.2860 \pm 1.535 \mathrm{E}-02$} & \multicolumn{2}{|c|}{$4.046 \mathrm{E}-02 \pm 2.208 \mathrm{E}-03$} & $14.76 \pm 0.5409$ \\
\hline 5 & \multicolumn{2}{|c|}{$0.3971 \pm 1.515 \mathrm{E}-02$} & \multicolumn{2}{|c|}{$4.198 \mathrm{E}-02 \pm 2.242 \mathrm{E}-03$} & $16.24 \pm 0.3640$ \\
\hline 7 & \multicolumn{2}{|c|}{$0.4421 \pm 1.345 \mathrm{E}-02$} & \multicolumn{2}{|c|}{$4.058 \mathrm{E}-02 \pm 1.881 \mathrm{E}-03$} & $16.65 \pm 0.4805$ \\
\hline 10 & \multicolumn{2}{|c|}{$0.4610 \pm 1.810 \mathrm{E}-02$} & \multicolumn{2}{|c|}{$4.285 \mathrm{E}-02 \pm 3.381 \mathrm{E}-03$} & $16.33 \pm 1.064$ \\
\hline \multirow{2}{*}{$\begin{array}{l}\text { Loading } \\
\text { force }\end{array}$} & \multicolumn{5}{|c|}{ Four-element model (Burgers) } \\
\hline & \multicolumn{3}{|c|}{$b\left(=\sigma_{0} / \eta_{v}\right)$} & $c\left(=\sigma_{0} / E_{r}\right)$ & $d\left(=T_{r}=\eta / E_{r}\right)$ \\
\hline $\mathrm{N}$ & \multicolumn{5}{|c|}{ Mean \pm SD } \\
\hline 1 & $0.1958 \pm 1.988 \mathrm{E}-02$ & 2.83 & $128 \mathrm{E}-05$ & $3.557 \mathrm{E}-02 \pm 3.138 \mathrm{E}-03$ & $5.980 \pm 0.3422$ \\
\hline 2 & $0.2808 \pm 1.554 \mathrm{E}-02$ & 2.88 & $417 \mathrm{E}-05$ & $3.045 \mathrm{E}-02 \pm 1.864 \mathrm{E}-03$ & $6.279 \pm 0.2184$ \\
\hline 5 & $0.3922 \pm 1.537 \mathrm{E}-02$ & 3.10 & $457 \mathrm{E}-05$ & $2.988 \mathrm{E}-02 \pm 1.675 \mathrm{E}-03$ & $6.799 \pm 0.2466$ \\
\hline 7 & $0.4376 \pm 1.365 \mathrm{E}-02$ & 3.01 & $412 \mathrm{E}-05$ & $2.848 \mathrm{E}-02 \pm 1.627 \mathrm{E}-03$ & $6.987 \pm 0.2406$ \\
\hline 10 & $0.4560 \pm 1.899 \mathrm{E}-02$ & 3.15 & $520 \mathrm{E}-05$ & $3.060 \mathrm{E}-02 \pm 4.065 \mathrm{E}-03$ & $6.897 \pm 0.6464$ \\
\hline
\end{tabular}

Model parameters $E_{0}, E_{r}, \eta$, and $\eta_{v}$ were correlated to loading force values (Figs. 4 and 5). The increasing rheological parameters might suggest the change of structure of gum candy under increasing stress. 

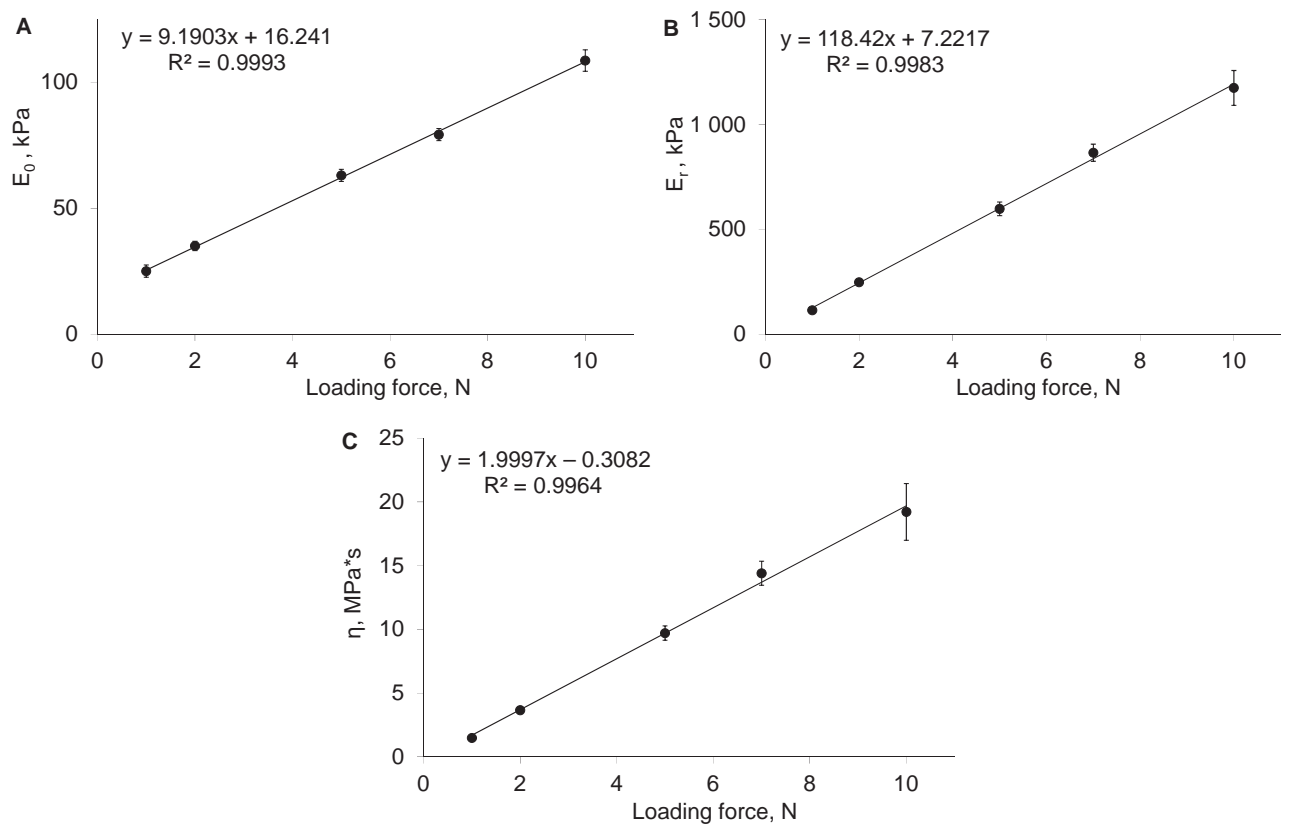

Fig. 4. Change of rheological parameters of three-element model as the function of loading force. A: $\mathrm{E}_{0}$ elastic modulus; $\mathrm{B}$ : $\mathrm{E}_{\mathrm{r}}$ elastic modulus; $\mathrm{C}: \eta$ viscous modulus
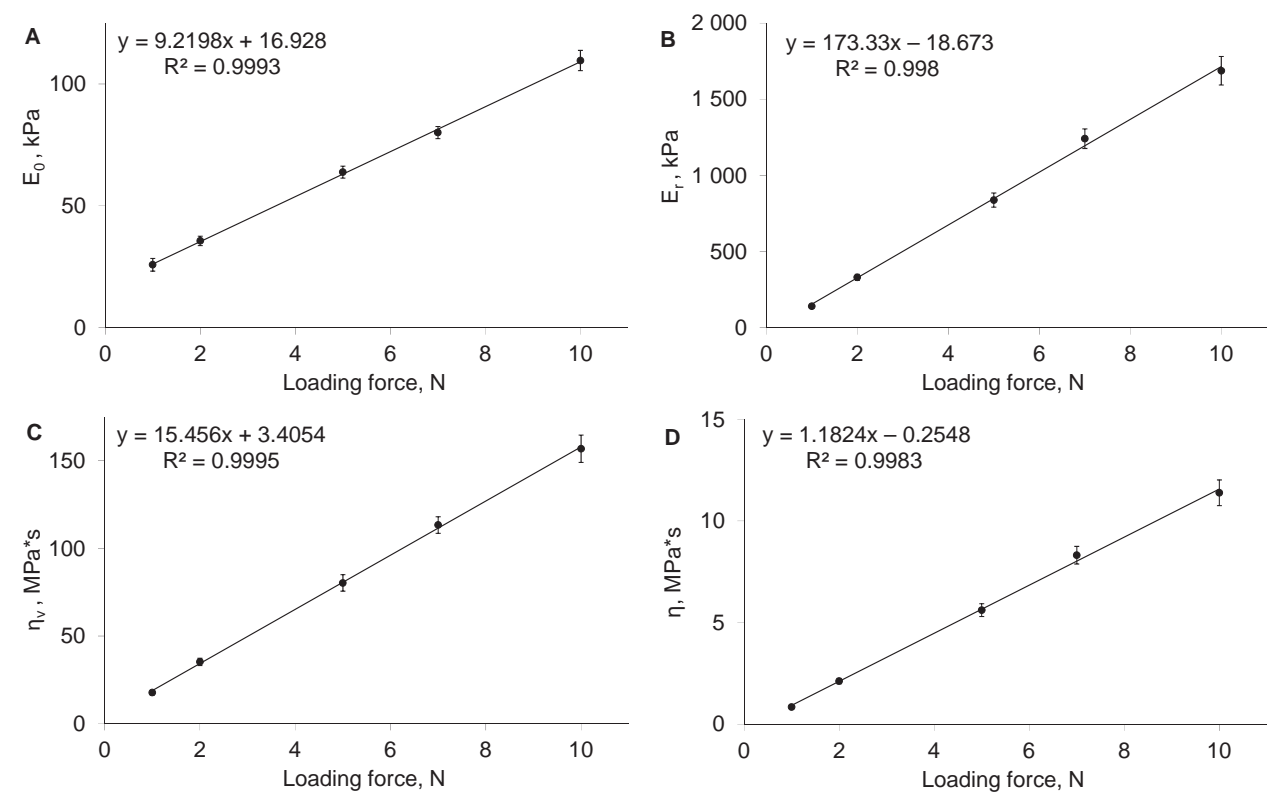

Fig. 5. Change of rheological parameters of Burgers model as the function of loading force. A: $E_{0}$ elastic modulus; $B: E_{r}$ elastic modulus; $C: \eta_{v}$ viscous modulus; $D: \eta$ viscous modulus 
The candy material is a complex protein-carbohydrate polymer mesh with bound water content (BUREY et al., 2009). Gels containing polysaccharide chains have no rubber elasticity, but gelatine gels behave like rubber (Mitchell, 1980). Under the increasing stress, the structure of the gum candy can be changed. One part of the non-covalent bonds is ruptured (Foegeding, 2007). Damage of the polymer mash and the changes in secondary binding between water and mesh also was observed (BUREY et al., 2009). The rheological properties of other confectionery products with such complex texture materials (as chocolate) can also show structure changes under various conditions (BICzó et al., 2013). Our earlier stress-strain measurements on gum candies with various speed of probe from $0.1 \mathrm{~mm} \mathrm{~s}^{-1}$ up to $1.1 \mathrm{~mm} \mathrm{~s}^{-1}$ could be described by a Maxwell-model containing an elastic element with elastic modulus depending on the stress (VOZÁRY et al., 2011). The increasing elastic modulus can be explained by cracking of gel structure in consequence of higher deformation speed (FoEGEDING, 2007).

The standard deviation of rheological parameters increased as a function of the applied stress (Figs. 4 and 5), meaning that under bigger stress the change of texture is bigger, while under less stress, the structure changes less.

\section{Conclusions}

The CRT, as a traditional measuring test, could be appropriate for rheological description of changes in gum candy material. By choosing the appropriate creeping time, loading force, and deformation speed, the follow up of the changes under stress in gum candy texture is possible. The plotted results show that the Burgers model could be a real model of gum candies, but the parameters of the Burgers model depend on the applied stress. Based on the linear correlation between the rheological parameters $\left(E_{0}, E_{r}, \eta, h_{v}\right)$ and the loading stress, the Burgers model can be developed in the future.

This work was sponsored by TÁMOP-4.2.1./B-09/1/KMR-2010-0005.

György Csima owes great thanks to Professor András Fekete, who as consultant supported his PhD work and his researches on the field of gel rheology for many years. Without Professor András Fekete's helpful support and assistance this article would not have been realized.

\section{References}

BAgley, E.B. (1983): Large deformations in testing and processing of food materials. In: Peleg, M. \& BAGLEy, E.B. (Eds), Physical properties of foods. Avi Publishing Co., Westport, CT, pp. 325-342.

Biczó, V., Fekete, A. \& Scherer, R. (2013): Influence of composition and storage conditions on chocolate hardness and heat resistance. Progr. Agric. Eng. Sci., 9, 55-73.

Burey, P., Bhandari, B.R., Rutgers, R.P.G., Halley, P.J. \& Torley, P.J. (2009): Confectionery gels: A review on formulation, rheological and structure aspects. Int. J. Food Prop., 12, 176-210.

Csima, Gy., Biczó, V., Kaszab, T. \& Fekete, A. (2010): Methods for the assessment of gum candy elasticity. XVII ${ }^{\text {th }}$ World Congress of the International Commission of Agricultural and Biosystems Engineering (CIGR), 13-17. June 2010, Québec City, Canada, paper: 101167

Csima, Gy. \& VozÁRY, E. (2013): Effect of measure settings on creep-recovery test results of gum candies. $3^{\text {rd }}$ Synergy Conference, 13-17. October 2013, Gödöllő, Hungary, Synergy 2013 - CD of Full Papers: paper N064-180 
DeMars, L.L. \& Ziegler, G.R. (2001): Texture and structure of gelatine/pectin-based gummy confections. Food Hydrocolloid., 15, 643-653.

Dénes, L.D., Zsom-Muha, V., Baranyai, L. \& Felföldi, J. (2012): Modelling of apple slice moisture content by optical methods. Acta Alimentaria, 41, Suppl. 1, 39-51.

Figura, L.O. \& TeixeIrA, A.A. (2007): Rheological properties. -in: Food Physics, Springer, pp. 181-185.

Foegeding, E.A. (2007): Rheology and sensory texture of biopolymer gels. Curr. Opin. Colloid In., 12, $242-250$.

Kaszab, T., Firtha, F. \& Fekete, A. (2008): Influence of non-ideal storage conditions on carrot moisture content loss. Progr. Agric. Eng. Sci., 4, 61-75.

Kaszab, T., KovÁcs, Z., SzÖllösi, D. \& Fekete, A. (2011): Prediction of carrot sensory attributes by mechanical tests and electronic tongue. Acta Alimentaria, 40, 41-58.

Lambert-Meretei, A., Szendrei, E., Nogula-Nagy, M. \& Fekete, A. (2010): Methods to evaluate the effects of bread improver additive on bread crumb texture properties. Acta Alimentaria, 39, 180-191.

Lau, M.H., TAng, J. \& Paulson, A.T. (2000): Texture profile and turbidity of gellan/gelatin mixed gels. Food Res. Int., 33, 665-671.

Marfil, P.H.M., Anhê, A.C.B.M. \& Telis, V.R.N. (2012): Texture and microstructure of gelatin/corn starch-based gummy confections. Food Biophys., 7, 236-243.

Mitchell, J.R. (1980): The rheology of gels (review paper). J. Texture Stud., 11, 315-337.

Moнos, F. (1993): Szakágazati édesipar II. (The class confectionery industry II.). Mezőgazdasági Szaktudás Kiadó, Budapest, pp. 127-135.

Moнos, F. (2010): Confectionery and chocolate engineering. Wiley-Blackwell, Oxford, pp. 137-139, 421-422.

SitKeI, Gy. (1981): A mezőgazdasági anyagok mechanikája. (Mechanics of agricultural materials). Akadémiai Kiadó, Budapest, pp. 108-132.

SzCZesniak, A.S. (2001): Texture is a sensory property. Food Qual. Prefer, 1(4), 215-225.

VozÁry, E., Krisán, Á. \& Csima, Gy. (2011): Rheological properties of gummy confections. PRAE Conference, 10-11. Oct. 2011, Nitra, Slovakia, Proceedings, pp. 150-154.

Zsivánovits, G. (2007): Pektinfilm reológiai tulajdonságai (Rheological properties of pectin film). Corvinus University of Budapest, PhD dissertation, 120 pages. 